\title{
Post Caesarean Wound sepsis and associated factors among patients attending a rural regional referral hospital in Western Uganda: A cross- sectional study
}

Ismael Muhumuza

Kampala International University - Western Campus

Abdulrahman Zeinul Lavingia

Kampala International University

Bekson Tayebwa

Kampala International University - Western Campus

Ahmed Abdulhussein Ahmed

Kampala International University - Western Campus

Farhiya Mohammed Koriow

Kampala International University - Western Campus

Victor Otieno Tetty

Kampala International University - Western Campus

Emmanuel Nzabandora

Kampala International University - Western Campus

Ubarnel Almenares

Kampala International University - Western Campus

Ivan Bonet Fonseca

Kampala International University - Western Campus

Victo Kyobutungi

Makerere University College of Health Sciences

John Turyagumanawe

Mbeya Referral Hospital

Collins Atuheire ( $\nabla$ atuheirecollinsgrace@gmail.com )

Makerere University https://orcid.org/0000-0002-5298-3892

Robinson Ssebuwufu

Kampala International University - Western Campus

Research article 
Keywords: post-caesarean wound sepsis, Uganda, cross-sectional study

Posted Date: February 24th, 2020

DOI: https://doi.org/10.21203/rs.2.24374/v1

License: (c) (i) This work is licensed under a Creative Commons Attribution 4.0 International License. Read Full License 


\section{Abstract}

Background : Post-caesarean wound sepsis is among the most common problem for patients who undergo caesarean section. It remains a common and widespread problem contributing to morbidity and mortality; this could be due to an increase in antimicrobial resistance. Determining the burden of wound sepsis and common bacterial pathogens can provide solution to prevent incidence and establish microbiological mapping.

Aim: To determine prevalence, identify factors, common bacterial pathogens from post-caesarean wounds and antibacterial susceptibility pattern at Hoima Regional Referral Hospital.

Methods : A cross-sectional study was conducted among post-caesarean mothers attending Hoima Regional Referral Hospital. Consecutive enrolment of 303 participants who consented to participate was done. Structured questionnaires were used to collect data on associated factors and wound swabs were done prior to bacterial culture. Antibacterial susceptibility pattern of isolated bacterial pathogens was determined by Kirby Bauer disc diffusion method. Data was analyzed using Stata 14.2.

Results : The wound sepsis rate was $16.8 \%$. Being educated, multiple vaginal examination, hygiene, previous caesarean sections and HIV seropositivity were all significantly and positively associated with post-caesarean wound sepsis $(\mathrm{p}<0.05)$. The most implicated bacteria was Staphylococcus aureus and was most susceptible to ciprofloxacin. Resistance was most exhibited against ciprofloxacin, gentamycin, ceftriaxone and cotrimoxazole especially by coliforms.

Conclusions. The rate of caesarean wound sepsis is high at Hoima Regional Referral Hospital . Being educated, multiple vaginal examination, hygiene, previous caesarean sections and HIV seropositivity are possible risk factors for the condition. Staphylococcus aureus is the commonest organism isolated from exudates of septic wounds after caesarean section. Awareness amongst health workers and patients about these major factors is necessary so that management can be directed. Rational use of antibiotics by health workers is paramount to combat resistance in this setting.

\section{Background}

Post-cesarean wound sepsis is common among women following cesarean section and this can easily progress into septic shock if poorly managed [1,2]. Early diagnosis of post-cesarean wound sepsis using sepsis biomarkers such as pro-calcitonin (PCT) is an important medical practice [3]. These biomarkers are hardly available in several health care units in developing countries and this has led to the development of a global campaign on development of appropriate guidelines for successful management of sepsis $[4,5]$. Successful management is crucial to ensure that unnecessary prolonged activation of the immune response is inhibited [6-8]. Though cesarean sections are done under aseptic conditions, the risk of post-cesarean wound sepsis always exists which puts post-cesarean wound sepsis among the most common nosocomial infections [9]. Globally, the rate of cesarean section is increasing rapidly [10] and the most common complication after cesarean section is wound sepsis, with an 
incidence of 3-15\% [11]. Post-cesarean wound sepsis is also associated with maternal mortality rate of up to $3 \%$ especially in health units that have no facilities to carryout safe cesarean sections or treat postcesarean complications [12].

In sub-Saharan Africa, post-cesarean wound sepsis has been shown to be in the range of $1.7 \%$ to $10.4 \%$ showing that the condition is significant in the continent $[13,14]$. This has been attributed to poor accessibility to health care services which is below $3 \%$ and thus resulting in poor postnatal follow up and wound care [15]. In addition, post-cesarean wound sepsis in sub Saharan Africa has been associated with poverty, environmental pollution, poor preoperative care, malnutrition, anemia, wound contamination, poor antibiotic selection and poor immunity [16]. In East Africa, the rate of cesarean sections is below $40 \%$, which is a higher rate [17] compared to the recommended rate of cesarean section as per the WHO which considers that the best cesarean section rate is between $10-15 \%$ [18]. This increases the risk of post-cesarean wound sepsis.

In Uganda, a study conducted in Jinja showed that the major pathogenic bacteria associated with postoperative sepsis are; Staphylococcus aureus, coliforms, Proteus mirabilis, Pseudomonas aeruginosa, Klebsiella pneumoniae and Enterobacterspp [19]. In addition, the study showed that these pathogens were highly resistant to ampicillin, amoxicillin and chloramphenicol. A study conducted at Mulago National Referral Hospital in Uganda showed that majority of these septic wounds have pathogens that are methicillin resistant thus posing a major healthcare challenge due to the limited class of drugs available in several healthcare centers in Uganda [20].

At Hoima Regional Referral Hospital (HRRH) there was a high turnover of patients with eight to ten cesarean sections done in a day (maternity theatre register). It was also noted that theatres were being shared by other surgical teams and that the patients with post-cesarean wound sepsis were not isolated from the rest of the patients in ward, according to the findings during an onsite visit to the Hospital.

Several associated factors including patient related factors, hospital factors and obstetric factors have made management of post-cesarean wound sepsis challenging, leading to an increase in hospital stays [21]. Hence, thorough identification of the bacterial pathogens and the associated factors of postcesarean wound sepsis is important for developing proper protocols to reduce its burden and complications.

\section{Methods}

\section{Study design}

We performed a descriptive and analytical cross-sectional study and we involved laboratory investigations to isolate the bacterial pathogens and antibacterial susceptibility pattern. The outcome variables were post-cesarean sepsis. We also assed predictors such as socio-demographic and clinical factors for the study participants. 


\section{Study site and setting}

The study was conducted in the postnatal ward at Hoima Regional Referral Hospital (HRRH) between the months of July to September 2018. HRRH is a public hospital located in Hoima District with in coordinates; $0124 \mathrm{~N}, 3118 \mathrm{E}$ and is approximately $230 \mathrm{~km}$ by road from Kampala (Capital city of Uganda). The major tribe is Banyoro and the main occupation is animal husbandry and crop farming.

Hoima Regional Referral Hospital is a well-established hospital and it offers both in-patient and outpatient services with a range of departments and clinics, including General Surgery, Orthopedics, Obstetrics and Gynecology and Internal Medicine. The hospital is well equipped with a bed capacity of 400. The Obstetrics and Gynecology Department of Hoima Regional Referral Hospital has four specialists, one Resident doctor, five intern doctors and 13 midwives. The obstetrics and gynecology department has 110 beds. The post-natal ward for post-cesarean mothers is located in the new block. The new block has about 60 beds which are always fully occupied with some patients lying on the floor.

According to the hospital records (Maternity Theatre register), Hoima Regional Referral Hospital performs approximately 8-10 cesarean sections per day. These are done in two theatres that are shared by other surgical teams. The hospital had a range of 10-20 vaginal deliveries per day and also offers antenatal and postnatal services. The main laboratory of Hoima Regional Referral Hospital consists of the following sections: hematology and blood bank, chemistry, parasitology and microbiology. It was composed of 20 staff members and these include three specialists, two laboratory technologists, eight laboratory technicians, six laboratory assistants, and one laboratory attendant. The microbiology laboratory was operated by one laboratory technologist, one laboratory technician, one laboratory assistant and one laboratory attendant. It was well equipped to carry out culture and sensitivity and other microbiological tests. Some of the equipment found in this laboratory were; autoclave, incubator, microscope, hot air oven, refrigerator, safety cabinet and gas cylinder.

\section{Study population}

The study population were mothers who have delivered by cesarean section at Hoima Regional Referral Hospital during the period of the study.

\section{Selection criteria}

\section{Inclusion Criteria}

All adult and emancipated mothers (on ward or re-admitted) who delivered by cesarean section at Hoima Regional Referral Hospital during the study period.

\section{Exclusion Criteria}

Cesarean section mothers from other health units that were referred to Hoima regional referral hospital were excluded due to limited access to their medical records. Mothers who would have had a re- 
exploration due to cesarean section complications other than suspected sepsis, as well as those who were in their early puerperium and those who reported after six weeks, were also excluded.

\section{Sample size}

The sample size for this study was 303 and was computed using modified Kish Leslie formula (Daniel, 1999).

\section{Sampling technique}

Consecutive enrollment of participants who consent to participate in the study. This was carried out on a daily basis until required sample size.

\section{Data collection instruments}

Structured investigator-administered pre-tested questionnaire was used for each participant to collect information on socio-demographic and known factors that may be related to the development of postcesarean wound sepsis in each patient including obstetric factors, hospital factors and health factors.

A detailed history was elicited (English), translated where necessary for women who did not understand English; and physical examination was performed. Presence or absence of post-cesarean wound discharge (exudate) was noted. Swabs for mothers with discharge were taken and cultured in the laboratory according to standard clinical laboratory guidelines. Susceptibility testing was carried out according to Kirby Baur diffusion methods.

\section{Sample collection and transportation}

Patients with post-cesarean wound sepsis who met the inclusion criteria of the study and were, educated, counseled about the study and then consented to participate. They were requested to allow history taking and physical examination and when a patient had post-cesarean wound discharge (Exudate), a sample was taken for microbiological analysis. Using sterile swab sticks, two samples from each participant were collected by gently rubbing the sterile swab sticks in the infected site (wound depth) using aseptic technique and immediately replaced inside the swab sticks case. The sterile swab stick was labeled with each participant's study number and transported to Microbiology laboratory immediately for processing, and in case of any delay, the sample was stored aerobically in the refrigerator at 4-8 $₫ \mathrm{C}$.

\section{Sample processing and Laboratory analysis}

\section{Isolation}

The collected samples were inoculated on blood agar, chocolate agar, MacConkey agar and mannitol salt agar. They were then incubated both aerobically and anaerobically at $37 \rrbracket \mathrm{C}$ for $24-48 \mathrm{hrs}$. Colony morphology was observed according to shape, size, elevation and margin and surface characteristics. 


\section{Direct Gram Microscopy}

A direct smear was made for Gram stain; a drop of sterile normal saline was added at the center of a clean dried glass slide and the swab containing the sample rolled in the drop of normal saline spreading it on the glass slide in a circular motion to make a thin smear of the size of a fifty shilling coin. The smear was allowed to air-dry and then heat-fixed by passing it at least three times over a Bunsen flame. The slide was placed on the staining rack and flooded with crystal violet solution for 60 seconds, washed with clean water and covered with Lugol's lodine (a mordant) and then allowed to act for a minute.

The slide was again washed in clean water and then decolorized with $50 \%$ acetone- alcohol under slow running tap water until a faint pink color was observed or no more color tend to flow from the smear. The process of decolorizing did not exceed 30 seconds. After decolorizing, the slide was washed in clean water and counterstained with neutral red solution. The slide was then washed in clean water; air-dried and observed under the microscope with x100 objective lens (oil immersion lens). Gram-positive bacteria was observed as blue or purple color and Gram-negative as red or pink color. Also, the morphology and shape of the bacteria was used to identify whether they are cocci, diplococcic, cocci in chains, clusters, and whether they are rods in appearance. Pus cells were also observed in the direct Gram-stained slide.

\section{Identification of bacterial isolates}

\section{Cultural characteristics}

The colony morphological characteristics of the bacterial isolates was observed as follows; color, margin, mucoid, texture, and hemolysis on blood agar medium, among others. This helped in determining the characteristics of the colonies of the bacteria on culture media such as Lactose or non-lactose fermenters on MacConkey agar and type of hemolysis (alpha, beta, and gamma hemolysis) on blood agar.

\section{Biochemical tests}

The isolates were identified using the conventional biochemical tests such as API (Analytical Profile Index) which depends on the Gram's stain reaction of the isolates (Gram-positive or Gram-negative bacteria). Other biochemical tests included catalase, optochin, bacitracin, coagulase, indole, citrate utilization, urea utilization, triple sugar iron agar fermentation, MR-VP test and oxidase as described below:

\section{Catalase test}

The Catalase Test was carried out to differentiate between Streptococcus and Staphylococcus species and this was done according to standard methods [22] . A drop of $3 \%$ hydrogen peroxide was added to a loop full of the test organisms. Presence of bubbles indicated catalase activity. Streptococcus species was catalase positive while Staphylococcus species was catalase negative.

\section{Indole test}


The Indole Test was carried out according to the method described by Cheesbrough [22] to determine the ability of the isolate to degrade amino acid tryptophan and produce tryptophanase enzyme. A $1 \%$ tryptophan broth in a test tube was inoculated with 7 days isolate and incubated at $37^{\circ} \mathrm{C}$ for 48 hours. After 48 hours, $1 \mathrm{ml}$ of chloroform was added to the broth. The test tube was shaken gently, and $2.1 \mathrm{ml}$ of Kovac's reagent was added and again shaken gently. This was allowed to stand for 20 minutes. The formation of red coloration at the top layer, indicated a positive test, while a yellow coloration indicated negative result. Escherichia coli and Proteus are indole-positive.

\section{Urease test}

The Urease test was carried out according to the method described by Cheesebrough [22] to determine the ability of the bacteria to hydrolyse urea and produce ammonia and carbon dioxide. The test organism were inoculated into urease broth and incubated at $30^{\circ} \mathrm{C}$ for 72 hours. Purplish pink coloration of the medium indicated a positive reaction for Proteus and negative for other enterobacteria like Klebsiella and E. coli.

\section{Citrate utilization}

This was carried out by inoculating the test organism in test tube containing Simon's citrate medium and incubated for 24 to 72 hours. The development of deep-blue color after incubation was indicate a positive result. Klebsiella species are citrate- positive.

\section{Triple sugar- iron test}

Triple sugar iron test was carried out according to the method described by Cheesbrough [22]; the test determined the ability of the organism to ferment the three sugar component of the medium: glucose, lactose and sucrose. The medium contains a pH indicator (phenol red) and a detection system (thiosulphate and ferrous sulphate) for hydrogen sulphide $\left(\mathrm{H}_{2} \mathrm{~S}\right)$. The medium was prepared as an agar slant. The test organism was inoculated by stabbing the medium using sterilized straight wire loop and the surface of the slope was also streaked with the test organism. The test was incubated at $37^{\circ} \mathrm{C}$ for 3 days. After incubation, gas production was determined by observing the cracking of the medium, and production of $\mathrm{H}_{2} \mathrm{~S}$ was observed by the blackening of the butt (bottom) of the medium. The triple-sugar iron-agar aided in identification of Escherichia coli which ferments all three sugars and produce acid, turning the media into yellow color. Proteus species produces $\mathrm{H}_{2} \mathrm{~S}$ which is indicated by black coloration of the media and fermentation at the butt of the tube.

\section{Methyl red - Voges - Proskauer test (MR-VP)}

Methyl red - Voges - Proskauer test (MR-VP) was carried out according to the method described by Cheesbrough [22]. It was used to determine the ability of the organisms to ferment glucose with production of acid. Five milliliters $(5 \mathrm{ml})$ of MR-VP broth were inoculated with the test organism and incubated for 48 to 72 hours at $37^{\circ} \mathrm{C}$. After incubation, 2 to 3 drops of methyl red test were added to $1 \mathrm{ml}$ 
of the broth. A red color signified a positive methyl red test, while yellow color signified a negative test. To what remained, five drops of $4 \%$ potassium hydroxide $(\mathrm{KOH})$ were added followed by fifteen drops of $5 \%$ $a$-naphthol in ethanol. The development of red color within 1 hour indicates VP positive test while no color change indicated VP negative test. Escherichia coli is methyl red positive and voges-proskauer negative.

\section{Coagulase test}

It was used to identify Staphylococcus aureus which produces the enzyme coagulase. The rapid slide test was done by placing a drop of distilled water on each end of slide. Then a colony of the test organism (previously checked by Gram-staining) was emulsified in each of the drops to make two thick suspensions. A loopful of plasma was added to one of the suspensions (no plasma was added to the second suspension), and mixed gently. Formation of clumps of the organisms within 10 seconds was indicative of a positive test while absence of these clumps was indicative of negative results.

For suspected Staphylococcus aureus isolates which turn negative for the rapid slide test, the test was done by emulsifying several isolated colonies of test organism in $1 \mathrm{ml}$ of diluted rabbit plasma (1:5) dilution to give a milky suspension. The tubes were then incubated at $35^{\circ} \mathrm{C}$ in water bath for 4 hours. These were then examined at intervals of 1, 2 and 4 hours for clot formation by tilting the tube through $90^{\circ}$. If the test was still negative, the tube was left at room temperature overnight and examined again for Staphylococcus aureus that produced a delayed clot.

\section{Oxidase test}

The test was used in identification of organisms which produce the enzyme cytochrome oxidase. A filter paper soaked with the substrate tetramethyl-p-phenylenediamine dihydrochloride was moistened with sterile distilled water. Using a glass rod, a colony of the test organism was smeared on the filter paper. The development of a blue-purple color within a 10 seconds was indicative of positive test while absence or formation of a blue-purple color after 10 seconds was considered negative. Pseudomonas species and Neisseria species are oxidase positive.

\section{Susceptibility Pattern Determination (Kirby-Bauer disc diffusion technique)}

The susceptibility pattern of the identified pathogens was determined by agar disc diffusion technique by Kirby-Bauer using Muller Hinton agar. The Muller Hinton agar was prepared according to the manufacturer's instructions under sterile conditions to avoid any contamination that may result. About 45 colonies of the organism were diluted in sterile peptone water and mixed and incubated for 4-5 minutes and its turbidity compared to a McFarland standard $0.5 \%$.

A prepared Muller Hinton agar was dried in an incubator for at least 15 minutes and using a sterile glass rod or swab stick, the surface were smeared with the diluted organism of the peptone water, and using sterile forceps, ten different antibiotic containing discs were placed on the dried surface of the Muller Hinton agar containing the organism and then placed in the incubator at $37 \otimes \mathbb{C}$ for 24 hours. 
The diameter of a clear zone surrounding the antibiotic disc was measured in millimeters and compared to a standard antibiotic chart for measuring zones of inhibition. Zones of inhibition measured were recorded as susceptible (S), Intermediate (I), and Resistant I according to the standard chart.

\section{Statistical analysis}

Data on questionnaires was entered in Microsoft Excel version 2010, and then data from Excel was exported to IBM SPSS statistics version 23 as well as STATA 14.1 (Statacorp, USA Texas). Sociodemographic and clinical factors were summarized as means and medians, standard deviations and interquartile range (for continuous variables). Proportions, percentages and frequencies were used for categorical variables using STATA 14.1.

Prevalence of post caesarian sepsis was summarized as frequencies and percentages. The factors associated with post-cesarean wound sepsis were assessed using binary logistic regression. For factors with odds ratio $\leq 0.2$ at bivariate and those with biological plausibility were transferred for multivariate analysis. Bar charts were used to present susceptibility profile.

\section{Quality control}

The questionnaires was checked for completeness before collection to ensure valid data is obtained. Two independent microbiologists were involved in identification bacterial isolates. Additionally, standard operating procedures were adhered to.

\section{Ethical considerations}

Permission to conduct this study was obtained from the department of obstetrics and gynecology and post graduate directorate. Afterwards approval was obtained from Kampala International University Research Ethics Committee (KIU-REC).

\section{Results}

\section{Socio-demographic characteristics of study participants attending Hoima Regional Referral Hospital}

Table 1. The median age was 23 years for both referred and non-referred study participants, with $92.2 \%$ married among the non-referred participants. Majority of the non-referred study participants had no formal education (56\%) compared to $24 \%$ among referred participants $(p=0.001)$. Farming was the major occupation (79\%) among the referred participants with $41 \%$ Anglicans were the majority among the nonreferred participants while believers of Bishaka faith were the minority $(<5 \%)$ in both groups.

\section{Clinical characteristics of study participants attending Hoima Regional Referred Hospital}

Table 2. The median BMI among non-referred participants is 27 compared to 26 in referred participants $(p=0.02)$. The prevalence of diabetes Mellitus, Hypertension, HIV and Cancer was low, i.e. $<1 \%,<7 \%,<3 \%$ and $<1 \%$ respectively. 


\section{Hospital and obstetric factors of women attending Hoima Regional Referral Hospital}

Table 3. In our study, intern doctors mainly handled caesarean sections for both referred and non-referred mothers attending Hoima Regional Referred Hospital. Emergency caesarean section were the majority in this setting with the most preferred type of incision being midline. Among $61 \%$ of non-referred patients, there were no antibiotics given before surgery compared to $42 \%$ among referred patients. Premature rupture of membranes was more among referred patients (13\%) compared to Premature rupture of membranes among non-referred patients $(p=0.03)$. Participants with more than one previous caesarean section were more in non-referred $29 \%$ compared to $25 \%$ in referred patient $(p=0.42)$

\section{Prevalence of post caesarean wound sepsis of women attending Hoima Regional Referral Hospital, western Uganda}

Table 4. In the study comprising 303 participants, $16.8 \%$ were diagnosed with post-caesarean wound sepsis with non-referred and referred participants having the condition of $11.7 \%$ and $27.6 \%$ respectively

\section{Bivariate and multivariate logistic regression analysis of post-caesarean wound sepsis on associated socio-demographic factors among non-referred patients attending Hoima Regional Referral Hospital}

Table 5. In the study single mothers were four times more likely to develop post-caesarean wound sepsis compared to married mothers ( $\mathrm{COR}=4.2,95 \% \mathrm{Cl} 1.0$ - 18.2). Mothers who completed primary education were six times more likely to develop post-caesarean wound sepsis compared to those who didn't attain formal education ( $\mathrm{cOR}=6.2,95 \% \mathrm{Cl} 1.8-21.4)$. Mothers who completed secondary level were ten times more likely to develop post-caesarean wound sepsis than those who didn't attain formal education ( $\mathrm{cOR}=10.2,95 \% \mathrm{Cl}$ 2.7-38.3). Mothers who completed tertiary education were ten times more likely to develop post-caesarean wound sepsis compared to those who didn't attain formal education (cOR=10.1, $95 \% \mathrm{Cl} 2.2-46.1$ ). Anglican mothers were $60 \%$ times less likely to develop post-caesarean wound sepsis than Catholics (cOR=0.4, 95\% $\mathrm{Cl} 0.1-0.2)$.

On adjusted analysis: Non-referred mothers who completed primary education were 5.5 times more likely to develop post-caesarean wound sepsis compared to those who never attained formal education $(\mathrm{aOR}=5.5,95 \% \mathrm{Cl}$ 1.5-20.2). Non-referred mothers who completed secondary level were 11.6 times more likely to develop post-caesarean wound sepsis compared to those who never attained formal education $(\mathrm{aOR}=11.6,95 \% \mathrm{Cl}$ 2.6-51.5). Non-referred mothers who completed tertiary level were 8.7 times more likely to develop post-caesarean wound sepsis compared to those who never attained formal education (aOR=8.7, 95\% Cl 1.8-43.1).

Bivariate and Multivariate logistic regression analysis of post-caesarean wound sepsis on associated clinical, hospital and obstetric factors among non-referred patients attending Hoima Regional Referral Hospital

Table 6. Mothers who are HIV positive were 8.5 times more likely to develop post-caesarean wound sepsis than those who are HIV negative $(\mathrm{cOR}=8.5,95 \% \mathrm{Cl} 1.6-44.7)$. Mothers who had prior caesarean section 
were 2.9 time more likely to develop post-caesarean wound sepsis than those without prior caesarean section (cOR=2.9, 95\% $\mathrm{Cl} 1.2-6.8)$.

On adjusted analysis: Non-referred mothers who were HIV positive were 6.4 times more likely to develop post-caesarean wound sepsis compared to those who were HIV negative (aOR=6.4, 95\% Cl 1.1-38.6). Nonreferred mothers who experienced more than 4 vaginal examinations were four times more likely to develop post-caesarean wound sepsis compared to those done four times or less (aOR=4.0, 95\% $\mathrm{Cl} 1.1$ 14.3). Mothers with prior caesarean section were 3.5 time more likely to develop post-caesarean wound sepsis compared to those without $(\mathrm{aOR}=3.5,95 \% \mathrm{Cl} 1.3-9.5)$

\section{Bivariate and multivariate logistic regression analysis of post-caesarean wound sepsis on associated socio-demographic factors among referred patients attending Hoima Regional Referral Hospital}

Table 7. Mothers who bathed more than two time were seven times more likely to develop post-caesarean wound sepsis compared to those who bathed two time or less (aOR $=7.0,95 \% \mathrm{Cl} 1.6-30.2)$. Referred Bishaka faith mothers were 6.8 times more likely to develop post-caesarean sepsis compared to catholics though it was statistically not significant ( $\mathrm{COR}=0.6,95 \% \mathrm{Cl} 0.6-71.7)$. Referred mothers who bathed more than two times were 3.3 times more likely to develop post-caesarean wound sepsis compared to those who bathed two times or less though it was statistically not significant (cOR=3.5, 95\% $\mathrm{Cl}$ 0.9-11.2). Referred mothers who were underweight were 1.3 times more likely to develop post-caesarean wound sepsis compared to those with normal BMI though it was statistically not significant ( $\mathrm{COR}=1.3,95 \% \mathrm{Cl}$ $0.5-3.4)$

\section{Bivariate and Multivariate logistic regression analysis of post-caesarean wound sepsis on associated clinical, hospital and obstetric factors among referred patients attending Hoima Regional Referral Hospital}

Table 8. Mothers who experienced more than four vaginal examinations were 3.8 times more likely to develop post-caesarean wound sepsis compared to those in whom four and less vaginal examinations were done ( $\mathrm{COR}=3.8,95 \% \mathrm{Cl} 1.5-9.8)$. Referred mothers who were HIV positive were 2.7 times more likely to develop post-caesarean wound sepsis compared to those who are HIV negative although there was no statistical significance ( $\mathrm{COR}=2.7,95 \% \mathrm{Cl}$ 0.2-44.5). Referred mothers who were hypertensive were 2.1 times more likely to develop post-caesarean wound sepsis compared to those without hypertension though there was no statistical significance ( $\mathrm{COR}=2.1,95 \% \mathrm{Cl}$ 0.4-10.0). Referred mothers who were given antibiotics before surgery were 2.1 times more likely to develop post-caesarean wound sepsis compared to those who never received antibiotic though there was no statistical significance (cOR=2.1,95\% $\mathrm{Cl} 0.8$ $5.3)$.

On adjusted analysis: Referred mothers who experienced more than four vaginal examinations were 6 times more likely to develop post-caesarean wound sepsis compared to those in whom four and less vaginal examinations were done $(\mathrm{aOR}=6.095 \% \mathrm{Cl} 1.9-18.9)$. 
Common bacterial pathogens that were isolated among study participants attending Hoima Regional Referral Hospital

Table 9. The most common bacterial isolates were Staphylococcus aureus $28.8 \%$, followed by E. coli, $21 \%$. The least was Proteus mirabilis.

Drug susceptibility pattern of bacterial isolates from septic wounds of mothers in Hoima Regional Referral Hospital, Uganda

Figure 1: Ciprofloxacin, gentamicin, ceftriaxone,penicillin and cotrimoxazole were the most resisted drugs by Staphylococcus aureus, E. coli and Klebsiella Pneumoniae.

Drug susceptibility pattern of bacterial isolates from septic wounds of mothers in Hoima Regional Referral Hospital, Uganda.

Figure 2: Imipenem was the most active drug on all organisms especially on E. coli, klebsiella pneumonae and Pseudomonas auruginosa.

Coliforms showed high susceptibility to imipenem followed by Staphylocccocus aureus to ciprofloxacin.

\section{Discussion}

Prevalence of post caesarean wound sepsis among mothers attending post-natal ward at Hoima Regional Referral Hospital, Western Uganda

In our study the overall prevalence of post-caesarean wound sepsis was $16.8 \%$. This was much higher than the reported Sub-Saharan Africa prevalence of 7.3\% [23]. The discrepancy could be due to small area of coverage within the population by the researcher as he only considered Burundi, DRC and Sierra Leone and generalized it to all Sub-Saharan Africa. Though Chu et al. [23] had a bigger sample size compared to this study, this study considered only one referral hospital. In addition, the current prevalence is also lower than that of $22.2 \%$ done in Kenyatta National Hospital [24]. This may be due to fact that $\mathrm{KNH}$ is the biggest national referral Hospital in East Africa handling more cases than HRRH.

Our study findings show that post-caesarean wound sepsis was higher among referred patients than nonreferred patients. This result could be due to complications such as obstructed labour that was higher among the referred patients $(48 \%, 47 / 98)$ and this may be attributed to the multiple vaginal examinations before caesarean section and delayed ambulation after surgery. Our findings agree with those by Sai et al where $70 \%$ of the cases in Government Hospital, Tirupati, Chitoor district, India were due to obstructed labor [25].

Risk factors of post caesarean wound sepsis among mothers attending Hoima Regional Referral Hospital, Western Uganda 
High level of education (primary and post primary) was a significant predictor of post- caesarean wound sepsis among non-referred patients. This is contrary to the findings by Apanga et al from Northern Ghana where mothers with higher level education were less likely to experience post caesarean sepsis compared to those with primary and lower education [26]. Our findings could be explained by noncompliance of educated mothers towards health education offered by health workers; in our setting there is the "we know it all" among the educated mothers (especially secondary school education) as compared to mothers with no formal education. Also it may be due to increased maternal requests for caesarean sections which is a risk factor for post-caesarean wound sepsis among educated mothers [27]. However, our findings are consistent with those obtained by Rajab et al in South Western Iran where mothers that had attained high school education were 1.4 times likely to have post-caesarean wound sepsis than those with lower school education [28].

Behaviourally, mothers (non-referred) who reported having over 2 baths per day were more likely to experience post-caesarean wound sepsis compared to their counterparts who reported to have two or less number baths per day. This is against biological plausibility and it is possible that baths taken may be unhygienic as our participants were culturally oriented who incorporate herbs in their baths and this increases chances of microbial contamination of the wound post-caesarean section [3]. Additionally, the study participants were from low income background and possibility of having no recommended bathing soap is likely. There is need to sensitise such mothers against use of herbal concoctions in their baths.

Mothers who experienced more than four vaginal examinations had increased risk of post caesarean sepsis compared to mothers who experienced less than 4 vaginal examinations. Our findings are consistent with findings by Hassan et al obtained among mothers attending Port Harcourt Teaching Hospital, Southern Nigeria [24, 29]. The similarity is the highest delivery rate between the two hospitals; Hoima Regional referral Hospital and Port Harcourt teaching Hospital. Frequent vaginal examinations are likely to introduce microbial pathogens during examination into uterus through the vagina.

In our study, mothers who were HIV positive were more likely to develop post-caesarean wound sepsis compared to HIV sero-negative mothers. Our findings are similar to those obtained by Marsel in Tygerberg Hospital, South Africa where HIV ART naïve patients were about 6 times more likely to experience postcaesarean sepsis [30]. This can be explained by immunosuppression associated with HIV positivity that facilitate bacterial infection in such mothers.

In our study, mothers who had a prior caesarean section were more likely to have post-caesarean wound sepsis compared to those with no prior caesarean section[31]. The explanation could be explained by several reasons: There are high chances of prolonged caesarean section for mothers with prior Caesarean section due to fibrosis and adhesion. Also, prolonged CS is likely to result into severe bleeding leading to anemia, delayed or no ambulation that have a significant role on risk of Post-caesarean wound sepsis [32].

We found out that antiseptic use (Savlon) was protective against post-caesarean wound sepsis among referred mothers and this is so because most of these mothers are from refugee camps (Kyangwali 
refugee resettlement) where they are supported with supplies like antiseptics. Our findings are consistent with those found by Kawakita and Landy in their review paper where use of Chlorhexidine (similar ingredient for savlon) as antiseptic was protective against post-caesarean wound sepsis [33].

We found that single mothers were more likely to have post-caesarean wound sepsis compared to the married mothers. This is possible because such mothers have got reduced care and support as compared to married ones. A similar study by Nansikombi has been observed among mothers in Mulago hospital, Kampala [34].

Mothers of Anglican Faith were 64\% less likely to have post-caesarean wound sepsis compared to Catholics. In Anglican settings, there are formed groups such as Mother's Union which hold regular discussions concerning guidance about maternal health and hygiene among other activities. This has a bearing on reducing post-caesarean sepsis. Conversely catholic faith is liberal about alcohol consumption and this may have an implication on the risk of post- caesarean wound sepsis among the catholic mothers [35].

\section{Common bacterial isolates}

We found common bacteria being Staphylococcus aureus followed by E. coli. These findings are in agreement with findings in central Uganda in which Staphylococcus aureus and coliforms have been shown to be common pathogens in post-caesarean wound sepsis [19] . In addition, in Zanzibar, Staphylococcus aureus and E. coli were found to be common pathogens in sepsis [36], showing similarities in the common pathogens of Tanzania and Uganda, this may be attributed to the fact that Staphylococcus is a normal skin flora, and may have contaminated the wound during caesarean section since most of the work was handled by intern doctors who possibly had poor surgical techniques. In addition, a study done by Matinyi et al revealed that Staphylococcus was the most common organism isolated in hospital environment especially the door handles(100\%) of Mbale Regional Referral Hospital, Eastern Uganda [37]. However findings are different from the study done in Muhimbili teaching Hospital [38], where the commonest organism isolated was Pseudomonas aeruginosa, this may be due to the difference in the standard of Hygiene (poor aseptic technique) as evidenced in this Hospital, since one nurse was responsible for cleaning and dressing 15 post-operative wounds hence putting patients at risk of cross infection.

\section{Drug susceptibility pattern of bacterial isolates}

In our study, coliforms showed high susceptibility to Imipenem followed by Staphylococcus aureus to Ciprofloxacin and this is comparable to a study done in Mbale Regional Referral Hospital, Eastern Uganda [37]. Furthermore, the study also showed that Staphylococcus aureus and other coliforms were resistant to Ciprofloxacin, Ceftriaxone, Gentamycin and Cotrimoxazole. This may be attributed to the fact that these drugs were the most erroneously prescribed medications among the study population in Hoima Regional Referral Hospital. These findings are similar to those found in Greece [39]. 
The study also showed that Staphylococcus aureus was also resistant to Tetracycline and Penicillin which was in agreement with a study conducted by Bebell et al in a Ugandan referral hospital [40] where over $80 \%$ antibacterial resistance to Penicillins among in postpartum mothers was reported. In addition, a study done in Mulago National Referral Hospital revealed a development of Staphylococcus aureus methicillin resistance in post-caesarean wound sepsis [20].

\section{Strengths and Weakness of the study}

It is the first documented study done at HRRH to report post-caesarean wound sepsis and associated bacterial organisms. Additionally, people who were re-admitted upon exudate were swabbed, so we minimized loss of follow-up and under reporting of Post-caesarean wound sepsis.

In our study, we did not swab the theater surfaces and aerial space to correlate environmental contamination and post-caesarean wound. We were unable to characterize the bacterial isolates at molecular level due to limited budget.

\section{Conclusions}

The prevalence of post-caesarean wound sepsis at Hoima Regional Referral Hospital is $16.8 \%$. The major significant risk factors of post-caesarean wound sepsis were: higher level of education, history of previous caesarean section, hygiene, obstructed labor, HIV seropositivity and multiple vaginal examinations prior to surgery. The most common bacterial pathogens were Staphylococcus aureus and the least was Proteus mirabilis. Resistance was highest for coliforms and Staphylococcus aureus against, ciprofloxacin, gentamycin, penicillin, ceftriaxone and cotrimoxazole.

\section{Recommendations}

The local hospital management should alert the health workers about the high prevalence of post caesarean sepsis at this hospital to devise means of controlling it.

Enhanced awareness to the health workers and the patients on the major risk factors of sepsis and attending to them during management.

Health workers should enhance hygiene amongst mothers before, during and after caesarean section. Community based engagements of Health workers on rational use of antibiotics is extremely necessary.

Additionally, further studies should be carried out to involve swabbing theater and aerial space to correlate environmental contamination and post-caesarean wound sepsis.

\section{References}

1. Kalisa, R., et al., Maternal near miss and quality of care in a rural Rwandan hospital. BMC pregnancy and childbirth, 2016. 16(1): p. 324. 
2. Morgan, J. and S. Roberts, Maternal sepsis. Obstetrics and Gynecology Clinics, 2013. 40(1): p. 69-87.

3. Neu, J. and J. Rushing, Cesarean versus vaginal delivery: long-term infant outcomes and the hygiene hypothesis. Clinics in perinatology, 2011. 38(2): p. 321-331.

4. Bloos, F. and K. Reinhart, Rapid diagnosis of sepsis. Virulence, 2014. 5(1): p. 154-160.

5. Dellinger, R., M. Levy, and A. Rhodes, Surviving Sepsis Campaign Guidelines Committee including the Pediatric, Subgroup (February 2013). Surviving sepsis campaign: international guidelines for management of severe sepsis and septic shock: 2012. Crit Care Med. 41(2): p. 580-637.

6. Jain, R., et al., Albumin: an overview of its place in current clinical practice. Indian J Anaesth, 2004. 48(6): p. 433-438.

7. Esmon, N.L., 11 Cardiovascular Biology Research Program. Oklahoma Medical Research Foundation, Oklahoma City, Oklahoma. 73104: p. 503-514.

8. Yealy, D.M., et al., Recognizing and managing sepsis: what needs to be done? BMC medicine, 2015. 13(1): p. 98.

9. Dlamini, L.D., et al., Antibiotic prophylaxis for caesarean section at a Ugandan hospital: a randomised clinical trial evaluating the effect of administration time on the incidence of postoperative infections. BMC pregnancy and childbirth, 2015. 15(1): p. 91.

10. Ostovar, R., et al., Developing criteria for cesarean section using the RAND appropriateness method. BMC pregnancy and childbirth, 2010. 10(1): p. 52.

11. Zuarez-Easton, S., et al., Postcesarean wound infection: prevalence, impact, prevention, and management challenges. International journal of women's health, 2017. 9: p. 81.

12. Mitchell, M.D., et al., Placental exosomes in normal and complicated pregnancy. American journal of obstetrics and gynecology, 2015. 213(4): p. S173-S181.

13. Chu, K., et al., Cesarean section rates and indications in sub-Saharan Africa: a multi-country study from Medecins sans Frontieres. PloS one, 2012. 7(9).

14. Harrison, M.S. and R.L. Goldenberg, Cesarean section in sub-Saharan Africa. Maternal health, neonatology and perinatology, 2016. 2(1): p. 6.

15. Irani, M. and S. Deering, Challenges affecting access to cesarean delivery and strategies to overcome them in low-income countries. International Journal of Gynecology \& Obstetrics, 2015. 131(1): p. 3034.

16. Gelaw, K.A., et al., Surgical site infection and its associated factors following cesarean section: a cross sectional study from a public hospital in Ethiopia. Patient safety in surgery, 2017. 11(1): p. 18.

17. Worjoloh, A., et al., Trends in cesarean section rates at a large East African referral hospital from 2005-2010. Open Journal of Obstetrics and Gynecology, 2012. 2(03): p. 255.

18. Morrison, J.J., J.M. Rennie, and P.J. Milton, Neonatal respiratory morbidity and mode of delivery at term: influence of timing of elective caesarean section. BJOG: An International Journal of Obstetrics \& Gynaecology, 1995. 102(2): p. 101-106. 
19. Anguzu, J. and D. Olila, Drug sensitivity patterns of bacterial isolates from septic post-operative wounds in a regional referral hospital in Uganda. African health sciences, 2007. 7(3).

20. Kateete, D.P., et al., High prevalence of methicillin resistant Staphylococcus aureus in the surgical units of Mulago hospital in Kampala, Uganda. BMC research notes, 2011. 4(1): p. 326.

21. Dhar, H., et al., A study of post-caesarean section wound infections in a regional referral hospital, Oman. Sultan Qaboos University Medical Journal, 2014. 14(2): p. e211.

22. Cheesbrough, M., Parasitological tests. District laboratory practice in tropical countries, Part, 1999. 1: p. 220-1.

23. Chu, K., R. Maine, and M. Trelles, Cesarean section surgical site infections in sub-Saharan Africa: a multi-country study from Medecins Sans Frontieres. World journal of surgery, 2015. 39(2): p. 350355.

24. Hassan, K.O. and J.O. Alegbeleye, Post Caesarean Section Wound Infection and Microbiological Pattern at the University of Port Harcourt Teaching Hospital, Southern Nigeria. Research in Obstetrics and Gynecology, 2018. 6(1): p. 1-8.

25. Sai, T.S., S. Seshasai, and M.K. Vasundhara, A study of short term (6weeks) wound complications after caesarean section. IJAR, 2016. 2(5): p. 567-571.

26. Apanga, P.A. and J.K. Awoonor-Williams, Predictors of caesarean section in Northern Ghana: a casecontrol study. Pan African Medical Journal, 2018. 29(1): p. 1-11.

27. Abebe, F.E., et al., Factors leading to cesarean section delivery at Felegehiwot referral hospital, Northwest Ethiopia: a retrospective record review. Reproductive health, 2015. 13(1): p. 6.

28. Rajabi, A., et al., Risk factors for C-section delivery and population attributable risk for $C$-section risk factors in Southwest of Iran: a prospective cohort study. Medical journal of the Islamic Republic of Iran, 2015. 29: p. 294.

29. Ononuju, C., et al., Risk factors and antibiogram of organisms causing puerperal sepsis in a tertiary health facility in Nigeria. Tropical Journal of Obstetrics and Gynaecology, 2015. 32(2): p. 73-82.

30. Coetzer, M., A retrospective audit of post-caesarean sepsis at Tygerberg Hospital. 2017, Stellenbosch: Stellenbosch University.

31. Henderson, E. and E. Love, Incidence of hospital-acquired infections associated with caesarean section. Journal of hospital infection, 1995. 29(4): p. 245-255.

32. Diamond, K.A., E.A. Bonney, and J.E. Myers, Caesarean section: techniques and complications. Obstetrics, Gynaecology \& Reproductive Medicine, 2014. 24(2): p. 39-44.

33. Kawakita, T. and H.J. Landy, Surgical site infections after cesarean delivery: epidemiology, prevention and treatment. Maternal health, neonatology and perinatology, 2017. 3(1): p. 12.

34. Nansikombi, S., Risk factors for post cesarean wound infection among mothers at Mulago national referral hospital-Uganda. 2015, International Health Sciences University.

35. Namuyimbwa, L., et al., Prevalence and associated factors of protein-energy wasting among patients with chronic kidney disease at Mulago hospital, Kampala-Uganda: a cross-sectional study. BMC 
nephrology, 2018. 19(1): p. 139.

36. Onken, A., et al., Prevalence and antimicrobial resistance of microbes causing bloodstream infections in Unguja, Zanzibar. PloS one, 2015. 10(12).

37. Matinyi, S., et al., Contamination of microbial pathogens and their antimicrobial pattern in operating theatres of peri-urban eastern Uganda: a cross-sectional study. BMC infectious diseases, 2018. 18(1): p. 460.

38. Manyahi, J., Bacteriological spectrum of post operative wound infections and their antibiogram in a Tertiary Hospital, Dar Es Salaam, Tanzania. 2012, Muhimbili University of Health and Allied Sciences.

39. Plachouras, D., et al., Dispensing of antibiotics without prescription in Greece, 2008: another link in the antibiotic resistance chain. Eurosurveillance, 2010. 15(7): p. 19488.

40. Bebell, L.M., et al., Antimicrobial-resistant infections among postpartum women at a Ugandan referral hospital. PloS one, 2017. 12(4).

\section{Abbreviations}

aOR adjusted Odds Ratio

APH Antepartum Hemorrhage

BMI Body Mass Index

Cl Confidence Interval

cOR crude Odds Ratio

CS Caesarean Section

E. coli Escherichia coli

HRRH Hoima Regional Referral Hospital

IQR Interquartile Range

KIU-REC Kampala International University Research Ethics Committee

KIU-WC Kampala International University- Western Campus

KNH Kenyatta National Hospital

LTCS Lower Transverse Caesarean Section

MRSA Methicillin-Resistant Staphylococcus aureus

PCT Pro-calcitonin 
RCOG Royal College of Obstetrics and Gynecology

Sd Standard Deviation

\section{Declarations}

\section{Acknowledgement}

We appreciate the administration of Hoima Regional Referral Hospital for their cooperation. Appreciation go to Theophilus Pius who assisted in the Microbiology Laboratory. Additionally our sincere appreciation go to Akankunda Sayuni and Mohammed Bituura Agaba for manuscript proof reading and financial support respectively. Finally thanks to Brenda T. Atuheire for providing a conducive room for manuscript writing.

\section{Funding}

This project was self-funded through all stages from project design, Questionnaire design, data collection, analysis and manuscript writing.

\section{Availability of Data and Materials}

Tables and figures have been provided as supplementary material.

The raw data are available upon reasonable request from the corresponding author.

\section{Contributions}

IM: Conceptualized the research idea, designed research and participated in drafting the manuscript. AZL, BT, AAA, FMK, JT \& VOT were helpful in providing technical assistance and proof reading the draft manuscript. EN, UA, IBF \& VK participated in proof reading the manuscript. CA \& RS were helpful in data analysis and drafting a manuscript.

\section{Ethics approval and consent to participate}

Study participants provided written informed consent. Approval to conduct this research was sought from Kampala International University Research \& Ethics committee and Hoima Regional Referral Hospital Research Ethics Committee. The reference number: UG-REC-023.

\section{Consent for publication}

Not applicable.

\section{Competing interests}


The authors declare that they have no competing interests.

\section{Tables}

Table 1: Socio-demographic characteristics of study participants attending Hoima Regional Referral Hospital

\begin{tabular}{|c|c|c|c|}
\hline \multirow[b]{2}{*}{ Variable } & \multicolumn{2}{|l|}{ Patient type } & \multirow[b]{2}{*}{$\mathrm{p}$-value } \\
\hline & $\begin{array}{l}\text { Non-referred } \\
(\mathrm{n}=205)\end{array}$ & Referred $(\mathrm{n}=98)$ & \\
\hline Median age in years (IQR) & $23(20-28)$ & $23(19-28)$ & 0.95 \\
\hline \multicolumn{4}{|l|}{ Marital status n (\%) } \\
\hline Married & $189(92.2)$ & 87(88.8) & 0.56 \\
\hline Single & $9(4.4)$ & $8(8.2)$ & 0.51 \\
\hline Divorced & $5(2.4)$ & $2(2.0)$ & 0.95 \\
\hline Cohabiting & $2(1.0)$ & $1(1.0)$ & 1.00 \\
\hline \multicolumn{4}{|l|}{ Education n (\%) } \\
\hline None & $115(56.1)$ & 23(23.5) & 0.001 \\
\hline Primary & $49(23.9)$ & $52(53.1)$ & 0.004 \\
\hline Secondary & $26(12.7)$ & 19(19.4) & 0.51 \\
\hline Tertiary & $15(7.3)$ & $4(4.1)$ & 0.075 \\
\hline \multicolumn{4}{|l|}{ Employment n (\%) } \\
\hline Farmer & $119(58.1)$ & $77(78.6)$ & 0.25 \\
\hline Health worker & $2(1.0)$ & $2(2.0)$ & 0.95 \\
\hline Saloon & $28(13.7)$ & $7(7.1)$ & 0.51 \\
\hline Teacher & $9(4.4)$ & $3(3.1)$ & 0.94 \\
\hline Others & 47(22.9) & $9(9.2)$ & 0.44 \\
\hline \multicolumn{4}{|l|}{ Religion n (\%) } \\
\hline Catholic & $68(33.2)$ & $39(39.80)$ & 0.75 \\
\hline Anglican & $84(41.0)$ & $32(32.7)$ & 0.69 \\
\hline Muslim & $15(7.32)$ & $4(4.1)$ & 0.88 \\
\hline SDA & $12(5.9)$ & $4(4.1)$ & 0.93 \\
\hline Bishaka & $7(3.4)$ & $4(4.1)$ & 0.97 \\
\hline Others & $19(9.3)$ & $15(15.3)$ & 0.78 \\
\hline $\begin{array}{l}\text { Median no. of times bathe a day } \\
\text { (sd) }\end{array}$ & $1.94(0.64)$ & $1.12(1.20$ & $<0.001$ \\
\hline
\end{tabular}

Table 2: Clinical characteristics of study participants attending Hoima Referral Hospital. 


\begin{tabular}{llll}
\hline & \multicolumn{2}{l}{ Patient type } & \\
\cline { 2 - 3 } & Non-referred $(\mathrm{n}=205)$ & Referred $(\mathrm{n}=98)$ & $\mathrm{p}$-value \\
\hline Median BMI (IQR) & $27(25.0-29.9)$ & $25.5(23.56-28.57)$ & 0.017 \\
History of diabetes & $204(99.51)$ & $98(100.0)$ & 0.31 \\
No & $1(0.49)$ & $0(0.0)$ & $<0.001$ \\
Yes & & $91(92.86)$ & 0.04 \\
History of hypertension & $202(98.5)$ & $7(7.14)$ & 0.04 \\
No & $3(1.46)$ & $96(98.0)$ & 0.63 \\
Yes & $199(97.1)$ & $2(2.0)$ & 0.63 \\
HIV & $6(2.9)$ & & \\
No & & $98(100.0)$ & 0.31 \\
Yes & $204(99.5)$ & $0(0.0)$ & - \\
History of cancer & $1(0.49)$ & & \\
No & & & \\
Yes & & & \\
\hline
\end{tabular}

Table 3: Hospital and obstetric factors of women attending Hoima regional referral Hospital 


\begin{tabular}{|c|c|c|c|}
\hline \multirow[b]{2}{*}{ Variable } & \multicolumn{2}{|l|}{ Patient type } & \multirow[b]{2}{*}{$\begin{array}{l}\mathrm{p}- \\
\text { value }\end{array}$} \\
\hline & $\begin{array}{l}\text { Non-referred } \\
(\mathrm{n}=205)\end{array}$ & $\begin{array}{l}\text { Referred } \\
(\mathrm{n}=98)\end{array}$ & \\
\hline \multicolumn{4}{|l|}{$\begin{array}{l}\text { Cadre that performed the surgery } \mathrm{n} \\
(\%)\end{array}$} \\
\hline Intern & 204(99.5) & 96(98.0) & 0.32 \\
\hline Medical officer & $1(0.49)$ & $2(2.0)$ & 0.06 \\
\hline \multicolumn{4}{|l|}{ Antibiotics given prior surgery } \\
\hline No & $124(60.5)$ & $41(41.8)$ & 0.02 \\
\hline Yes & $81(39.5)$ & $57(58.2)$ & 0.02 \\
\hline Median length of labor in hours (IQR) & $9(6-13)$ & $10(6-18)$ & 0.07 \\
\hline Median parity (IQR) & $2(1-3)$ & $2(1-4)$ & 0.30 \\
\hline \multicolumn{4}{|l|}{ Type of incision } \\
\hline Transverse & $86(42.0)$ & $34(34.7)$ & 0.16 \\
\hline Midline & $119(58.1)$ & $64(65.3)$ & 0.23 \\
\hline $\begin{array}{l}\text { Median no. of vaginal examination } \\
\text { (IQR) }\end{array}$ & $3(2-4)$ & $2(1-5)$ & 0.057 \\
\hline \multicolumn{4}{|l|}{ Type of c/section n (\%) } \\
\hline Emergency & $190(92.7)$ & $94(95.9)$ & 0.24 \\
\hline Elective & $15(7.3)$ & $4(4.1)$ & 0.24 \\
\hline \multicolumn{4}{|l|}{ Techniques of CS n (\%) } \\
\hline Classical & $5(2.44)$ & $6(6.12)$ & 0.17 \\
\hline LTCS & $200(97.56)$ & $92(93.9)$ & 0.17 \\
\hline \multicolumn{4}{|l|}{ Premature rapture of membrane } \\
\hline No & 193(95.1) & $85(86.7)$ & 0.03 \\
\hline Yes & $10(4.9)$ & $13(13.3)$ & 0.03 \\
\hline \multicolumn{4}{|l|}{ Previous CS } \\
\hline 1 & $146(71.22)$ & $74(75.5)$ & 0.42 \\
\hline$>1$ & $59(28.8)$ & $24(24.5)$ & 0.42 \\
\hline
\end{tabular}

Table 4: Prevalence of post-caesarean wound sepsis of women attending Hoima Regional Referred Hospital, western Uganda

\begin{tabular}{|c|c|c|c|c|c|c|}
\hline \multirow[b]{2}{*}{$\begin{array}{l}\text { Overall } \\
(\mathrm{n}=303)\end{array}$} & \multirow[b]{2}{*}{ prevalence } & \multicolumn{4}{|c|}{ Patient type } & \multirow[b]{2}{*}{$\begin{array}{l}\mathrm{p}- \\
\text { value }\end{array}$} \\
\hline & & Non-referr & $d(n=205)$ & Referred & $=98)$ & \\
\hline Frequency & $\%(95 \% \mathrm{CI})$ & Frequency & $\%(95 \% \mathrm{CI})$ & Frequency & $\%(95 \% \mathrm{CI})$ & \\
\hline 51 & $\begin{array}{l}16.8(13.0- \\
21.5)\end{array}$ & 24 & $\begin{array}{l}11.7(7.9- \\
16.9)\end{array}$ & 27 & $\begin{array}{l}27.6(19.4- \\
37.4)\end{array}$ & $0.002^{\mathrm{a}}$ \\
\hline
\end{tabular}

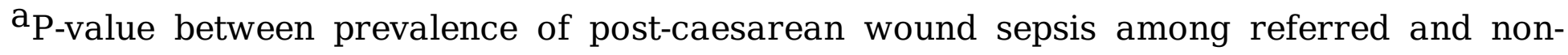
referred patients 
Table 5: Bivariate logistic regression analysis of post-caesarean wound sepsis on associated socio-demographic factors among non-referred patients attending Hoima Regional Referral Hospital 


\begin{tabular}{|c|c|c|c|c|c|c|}
\hline \multirow[b]{2}{*}{ Variable n (\%) } & \multirow[b]{2}{*}{$\begin{array}{ll}\text { No } & \text { sepsis } \\
(\mathrm{n}=181) & \end{array}$} & \multirow[b]{2}{*}{$\begin{array}{l}\text { Sepsis } \\
(n=24)\end{array}$} & \multicolumn{2}{|l|}{ Crude analysis } & \multicolumn{2}{|c|}{ Adjusted analysis } \\
\hline & & & cOR(95\%CI) & $\begin{array}{l}\mathrm{p}- \\
\text { value }\end{array}$ & aOR $(95 \% \mathrm{CI})$ & $\begin{array}{l}\mathrm{p}- \\
\text { value }\end{array}$ \\
\hline \multicolumn{7}{|c|}{ Age in years n (\%) } \\
\hline $18-23$ & $42(89.4)$ & $5(10.6)$ & 1.00 & & & \\
\hline $24-28$ & $43(86.0)$ & $7(14.0)$ & $\begin{array}{l}1.37(0.40- \\
4.65)\end{array}$ & 0.62 & & \\
\hline$>28$ & $96(88.9)$ & $12(11.1)$ & $\begin{array}{l}1.10(0.35- \\
3.17)\end{array}$ & 0.93 & & \\
\hline \multicolumn{7}{|l|}{ Marital status } \\
\hline Married & $169(89.4)$ & $20(10.6)$ & 1.00 & - & & \\
\hline Single & $6(66.7)$ & $3(33.3)$ & $\begin{array}{l}4.23(1.00- \\
18.22\end{array}$ & 0.05 & & \\
\hline Divorced & $4(80.0)$ & $1(20.0)$ & $\begin{array}{l}2.11(0.22- \\
19.8)\end{array}$ & 0.51 & & \\
\hline Cohabiting & $2(100.0)$ & $0(0.0)$ & - & & & \\
\hline \multicolumn{7}{|l|}{ Education } \\
\hline None & $111(96.5)$ & $4(3.5)$ & 1.00 & & 1.00 & \\
\hline Primary & $40(81.6)$ & $9(18.4)$ & $\begin{array}{l}6.24(1.82- \\
21.40)\end{array}$ & 0.004 & $\begin{array}{l}5.50(1.50- \\
20.17)\end{array}$ & 0.01 \\
\hline Secondary & $19(73.1)$ & $7(26.9)$ & $\begin{array}{l}10.22(2.73- \\
38.32)\end{array}$ & 0.001 & $\begin{array}{l}11.6(2.62- \\
5.45)\end{array}$ & 0.001 \\
\hline Tertiary & 11(73.3) & $4(26.7)$ & $\begin{array}{l}10.09(2.21- \\
46.05)\end{array}$ & 0.003 & $\begin{array}{l}8.73(1.77- \\
43.15)\end{array}$ & 0.008 \\
\hline \multicolumn{7}{|l|}{ Employment } \\
\hline Farmer & 107(89.9) & $12(10.1)$ & 1.00 & & & \\
\hline Health worker & $2(100.0)$ & $0(0.0)$ & - & & & \\
\hline Saloon & $25(89.3)$ & $3(10.7)$ & $\begin{array}{l}1.07(0.28- \\
4.08)\end{array}$ & 0.92 & & \\
\hline Teacher & $7(77.8)$ & $2(22.2)$ & $\begin{array}{l}2.55(0.47- \\
13.68)\end{array}$ & 0.28 & & \\
\hline Others & $40(85.1)$ & $7(14.9)$ & $\begin{array}{l}1.56(0.57- \\
4.24)\end{array}$ & 0.38 & & \\
\hline \multicolumn{7}{|l|}{ Religion } \\
\hline Catholic & $56(82.3)$ & $12(17.7)$ & 1.0 & & & \\
\hline Anglican & 78(92.9) & $6(7.1)$ & $0.36(0.13-1.0)$ & 0.05 & & \\
\hline Muslim & $14(93.3)$ & $1(6.7)$ & $\begin{array}{l}0.33(0.04- \\
2.78)\end{array}$ & 0.31 & & \\
\hline SDA & $10(83.3)$ & $2(16.7)$ & $\begin{array}{l}0.93(0.18- \\
4.82)\end{array}$ & 0.93 & & \\
\hline Bishaka & $6(85.7)$ & $1(14.3)$ & $\begin{array}{l}0.78(0.09- \\
7.07)\end{array}$ & 0.82 & & \\
\hline Other & $17(89.5)$ & $2(10.5)$ & $\begin{array}{l}0.55(0.11- \\
2.70)\end{array}$ & 0.46 & & \\
\hline
\end{tabular}

Number of times bathed per day n (\%) 
$\leq 2$

$>2$

BMI

Normal (18.5-25)

underweight $<18.5$

Overweight $>25$
165(88.2)

16(88.9)

$46(90.2)$

$0(0.00)$

134(88.2)
22(11.8) $\quad 1.00$

$2(11.1) \quad 0.94(0.20-\quad 0.69$

4.35)

$5(9.8) \quad 1.00$

$1(100.0) \quad-$

18(11.8) $\quad 1.24(0.43-\quad 0.69$

3.52)

Table 6: Bivariate and Multivariate logistic regression analysis of post-caesarean sepsis on associated clinical, hospital and obstetric factors among non-referred patients attending Hoima Regional Referred Hospital 


\begin{tabular}{|c|c|c|c|c|c|c|}
\hline \multirow[b]{2}{*}{ Variable n (\%) } & \multirow[b]{2}{*}{$\begin{array}{l}\text { No } \\
(n=181)\end{array}$} & \multirow[b]{2}{*}{$\begin{array}{l}\text { Sepsis } \\
(n=24)\end{array}$} & \multicolumn{2}{|l|}{ Crude analysis } & \multicolumn{2}{|c|}{ Adjusted analysis } \\
\hline & & & cOR (95\%CI) & $\begin{array}{l}\mathrm{p} \text { - } \\
\text { value }\end{array}$ & $\mathrm{aOR}(95 \% \mathrm{CI})$ & $\begin{array}{l}\mathrm{p} \text { - } \\
\text { value }\end{array}$ \\
\hline \multicolumn{7}{|c|}{ History of hypertension } \\
\hline No & $179(88.6)$ & $23(11.4)$ & 1.00 & & & \\
\hline Yes & $2(66.7)$ & $1(33.3)$ & $\begin{array}{l}3.89(0.34- \\
44.62)\end{array}$ & 0.28 & & \\
\hline \multicolumn{7}{|l|}{ HIV } \\
\hline Negative & 178(89.4) & $21(10.6)$ & 1.00 & & 1.00 & \\
\hline Positive & $3(50.0)$ & $3(50.0)$ & $\begin{array}{l}8.48(1.61- \\
44.71)\end{array}$ & 0.012 & $\begin{array}{l}6.35(1.05- \\
38.62)\end{array}$ & 0.045 \\
\hline \multicolumn{7}{|l|}{$\begin{array}{l}\text { Antibiotics given prior } \\
\text { surgery }\end{array}$} \\
\hline No & $111(88.0)$ & $14(11.2)$ & 1.00 & & & \\
\hline Yes & $70(87.5)$ & $10(12.50)$ & $\begin{array}{l}1.13(0.48- \\
2.69)\end{array}$ & 0.78 & & \\
\hline \multicolumn{7}{|c|}{ Length of labor in hours } \\
\hline$<12$ & $126(86.3)$ & $20(13.70)$ & 1.00 & & & \\
\hline$>12$ & $49(92.5)$ & $4(7.6)$ & $\begin{array}{l}0.51(0.17- \\
1.58)\end{array}$ & 0.25 & & \\
\hline \multicolumn{7}{|l|}{ Parity } \\
\hline Primi-para 1 & $62(87.3)$ & $9(12.7)$ & 1.00 & & & \\
\hline Multipara (2-4) & $10(89.8)$ & $12(10.2)$ & $\begin{array}{l}0.78(0.31- \\
1.96)\end{array}$ & 0.60 & & \\
\hline Grand Multipara $>4$ & $13(81.3)$ & $3(18.8)$ & $\begin{array}{l}1.59(0.38- \\
6.69)\end{array}$ & 0.53 & & \\
\hline \multicolumn{7}{|l|}{ Type of incision } \\
\hline Transverse & $77(89.5)$ & $9(10.5)$ & 1.00 & & & \\
\hline Midline & $104(87.4)$ & $15(12.6)$ & $\begin{array}{l}2.60(0.51- \\
2.97)\end{array}$ & 0.64 & & \\
\hline \multicolumn{7}{|c|}{ Times vaginal examination } \\
\hline$\leq 4$ & 158(89.3) & $19(10.5)$ & 1.00 & & 1.00 & \\
\hline$>4$ & $16(76.2)$ & $5(23.8)$ & $\begin{array}{l}2.60(0.86- \\
7.90)\end{array}$ & 0.092 & $\begin{array}{l}4.00(1.10- \\
14.28)\end{array}$ & 0.035 \\
\hline \multicolumn{7}{|l|}{ Types of CS } \\
\hline Emergency & $168(88.4)$ & $22(11.6)$ & 1.00 & & & \\
\hline Elective & $13(86.7)$ & $2(13.3)$ & $\begin{array}{l}1.17(0.25- \\
5.56)\end{array}$ & 0.84 & & \\
\hline \multicolumn{7}{|l|}{ PROM } \\
\hline No & $170(88.1)$ & $23(11.9)$ & 1.00 & & & \\
\hline Yes & $9(90.0)$ & $1(10.0)$ & $\begin{array}{l}0.82(0.10- \\
6.78)\end{array}$ & 0.86 & & \\
\hline \multicolumn{7}{|l|}{ Prior CS } \\
\hline No & $134(91.8)$ & $12(8.2)$ & 1.00 & & 1.00 & \\
\hline Yes & $47(79.7)$ & $12(20.3)$ & $\begin{array}{l}2.85(1.20- \\
6.78)\end{array}$ & 0.018 & $\begin{array}{l}3.46(1.26- \\
9.46)\end{array}$ & 0.016 \\
\hline \multicolumn{7}{|l|}{ Use of antiseptic } \\
\hline No & $34(82.9)$ & $7(17.1)$ & 1.00 & & 1.00 & \\
\hline Yes & 147(89.6) & $17(10.4)$ & $\begin{array}{l}0.56(0.22- \\
1.46) \\
\end{array}$ & 0.24 & $\begin{array}{l}0.53(0.16- \\
1.83) \\
\end{array}$ & 0.32 \\
\hline
\end{tabular}


Table 7: Bivariate and multivariate logistic regression analysis of post-caesarean wound sepsis on associated socio-demographic factors among referred patients attending Hoima Regional Referral Hospital 


\begin{tabular}{|c|c|c|c|c|c|c|}
\hline \multirow[b]{2}{*}{ Variable n (\%) } & \multirow[b]{2}{*}{$\begin{array}{l}\text { No } \\
(\mathrm{n}=71)\end{array}$} & \multirow[b]{2}{*}{$\begin{array}{l}\text { Sepsis } \\
(\mathrm{n}=27)\end{array}$} & \multicolumn{2}{|l|}{ Crude analysis } & \multicolumn{2}{|c|}{ Adjusted analysis } \\
\hline & & & cOR(95\%CI) & $\mathrm{p}$-value & aOR (95\%CI) & $\begin{array}{l}\text { - } \\
\text { value }\end{array}$ \\
\hline \multicolumn{7}{|l|}{ Age in years } \\
\hline $18-23$ & $16(76.2)$ & $5(23.8)$ & 1.00 & & & \\
\hline $24-28$ & $20(80.0)$ & $5(20.0)$ & $0.8(0.20-3.25)$ & 0.76 & & \\
\hline$>29$ & $35(67.3)$ & 17(32.7) & $\begin{array}{l}1.55(0.49- \\
4.95)\end{array}$ & 0.46 & & \\
\hline \multicolumn{7}{|l|}{ Marital status } \\
\hline Married & $62(71.3)$ & $25(28.7)$ & 1.00 & & & \\
\hline Single & $6(75.0)$ & $2(25.0)$ & $\begin{array}{l}0.83(0.20- \\
3.25)\end{array}$ & 0.76 & & \\
\hline Divorced & $2(100.0)$ & $0(0.00)$ & - & & & \\
\hline Cohabiting & $1(100.0)$ & $0(0.0)$ & - & & & \\
\hline \multicolumn{7}{|l|}{ Education } \\
\hline None & 18(78.3) & $5(21.7)$ & 1.00 & & & \\
\hline Primary & $38(73.1)$ & $14(26.9)$ & $\begin{array}{l}1.33(0.41- \\
4.25)\end{array}$ & 0.64 & & \\
\hline Secondary & $12(63.2)$ & $7(36.8)$ & $2.1(0.54-8.19)$ & 0.29 & & \\
\hline Tertiary & $3(75.0)$ & $1(25.0)$ & $\begin{array}{l}1.1(0.10- \\
14.19)\end{array}$ & 0.89 & & \\
\hline \multicolumn{7}{|l|}{ Employment } \\
\hline Farmer & $54(70.1)$ & 23(29.9) & 1.00 & & & \\
\hline Health worker & $2(100.0)$ & $0(0.0)$ & - & & & \\
\hline Saloon & $6(85.7)$ & $1(14.3)$ & $\begin{array}{l}0.39(0.04- \\
3.44)\end{array}$ & 0.40 & & \\
\hline Teacher & $2(66.7)$ & $1(33.3)$ & $\begin{array}{l}1.17(0.10- \\
13.60)\end{array}$ & 0.90 & & \\
\hline Others & $7(77.8)$ & $2(22.2)$ & $\begin{array}{l}0.68(0.13- \\
3.48)\end{array}$ & 0.63 & & \\
\hline \multicolumn{7}{|l|}{ Religion } \\
\hline Catholic & $27(69.2)$ & $12(30.8)$ & 1.00 & & & \\
\hline Anglican & $25(78.1)$ & $7(21.9)$ & $\begin{array}{l}0.63(0.21- \\
1.85)\end{array}$ & 0.40 & & \\
\hline Muslim & $3(75)$ & 1(25) & $\begin{array}{l}0.75(0.07- \\
7.79)\end{array}$ & 0.81 & & \\
\hline SDA & $3(75)$ & $1(25)$ & $\begin{array}{l}0.75(0.07- \\
7.97)\end{array}$ & 0.81 & & \\
\hline Bishaka & $1(25)$ & $3(75)$ & $\begin{array}{l}\text { 6.75(0.64- } \\
71.71)\end{array}$ & 0.11 & & \\
\hline Others & $12(80.0)$ & $3(20)$ & $\begin{array}{l}0.56(0.13- \\
2.37)\end{array}$ & 0.43 & & \\
\hline \multicolumn{7}{|c|}{$\begin{array}{l}\text { Number of time bathed per } \\
\text { day }\end{array}$} \\
\hline$\leq 2$ & $65(76.5)$ & $20(23.5)$ & 1.00 & & 1.00 & \\
\hline$>2$ & $6(50.0)$ & $6(50.0)$ & $\begin{array}{l}3.25(0.94- \\
11.20)\end{array}$ & 0.062 & $\begin{array}{l}\text { 6.95(1.60- } \\
30.18)\end{array}$ & 0.01 \\
\hline \multicolumn{7}{|l|}{ BMI } \\
\hline Normal & $29(76.3)$ & $9(23.7)$ & 1.00 & - & - & \\
\hline$<18.5$ & $1(100.0)$ & $0(0.0)$ & 1.34 & $0.52-$ & 0.54 & \\
\hline
\end{tabular}


Table 8:Crude and adjusted logistic regression analysis of post-caesarean sepsis on clinical, hospital and obstetric factors among referred patients attending Hoima Regional Referral Hospital 


\begin{tabular}{|c|c|c|c|c|c|c|}
\hline Variable n (\%) & $\begin{array}{ll}\text { No } & \text { sepsis } \\
(\mathrm{n}=71) & \\
\end{array}$ & $\begin{array}{l}\text { Sepsis } \\
(\mathrm{n}=27)\end{array}$ & cOR $(95 \% \mathrm{CI})$ & $\begin{array}{l}\mathrm{p}- \\
\text { value }\end{array}$ & $\mathrm{aOR}(95 \% \mathrm{CI})$ & $\begin{array}{l}\mathrm{p}- \\
\text { value }\end{array}$ \\
\hline \multicolumn{7}{|c|}{ History of hypertension } \\
\hline No & 67(73.6) & $24(27.1)$ & 1.00 & & & \\
\hline Yes & $3(57.1)$ & $3(42.9)$ & $\begin{array}{l}2.09(0.44- \\
10.04)\end{array}$ & 0.49 & & \\
\hline \multicolumn{7}{|l|}{ HIV } \\
\hline Negative & $70(72.9)$ & $26(27.1)$ & 1.00 & & 1.00 & \\
\hline Positive & $1(50.0)$ & $1(50.0)$ & $\begin{array}{l}2.69(0.16- \\
44.64)\end{array}$ & 0.49 & $\begin{array}{l}0.54(0.02- \\
22.68)\end{array}$ & 0.69 \\
\hline \multicolumn{7}{|c|}{$\begin{array}{l}\text { Antibiotics given before } \\
\text { surgery }\end{array}$} \\
\hline No & $33(80.5)$ & $8(19.5)$ & 1.00 & & & \\
\hline Yes & $38(66.7)$ & 19(33.3) & $\begin{array}{l}2.06(0.80- \\
5.33)\end{array}$ & 0.14 & & \\
\hline \multicolumn{7}{|c|}{ Length of labor in hours } \\
\hline$\leq 12$ & $44(75.9)$ & $14(24.1)$ & 1.00 & - & & \\
\hline$>12$ & $27(67.5)$ & $13(32.5)$ & $\begin{array}{l}1.51(0.62- \\
3.70)\end{array}$ & 0.36 & & \\
\hline \multicolumn{7}{|l|}{ Parity } \\
\hline Primi-para & $23(63.9)$ & $13(36.1)$ & 1.00 & - & & \\
\hline Multipara & $32(74.4)$ & $11(25.6)$ & $\begin{array}{l}0.61(0.23- \\
1.60)\end{array}$ & 0.31 & & \\
\hline Grad Multipara & $16(84.2)$ & $3(15.8)$ & $\begin{array}{l}0.33(0.08- \\
1.36)\end{array}$ & 0.13 & & \\
\hline \multicolumn{7}{|l|}{ Type of incision } \\
\hline Transverse & $26(76.5)$ & $8(23.5)$ & 1.00 & & & \\
\hline Midline & $45(70.3)$ & 19(29.7) & $\begin{array}{l}1.37(0.51- \\
3.57)\end{array}$ & 0.52 & & \\
\hline \multicolumn{7}{|c|}{$\begin{array}{l}\text { No. of vaginal examination } \\
\text { made }\end{array}$} \\
\hline$\leq 4$ & $57(80.3)$ & 14(19.7) & 1.00 & & 1.00 & \\
\hline$>4$ & $14(51.9)$ & $13(48.1)$ & $\begin{array}{l}3.78(1.46- \\
9.82)\end{array}$ & 0.006 & $\begin{array}{l}6.04(1.93- \\
18.96)\end{array}$ & 0.002 \\
\hline \multicolumn{7}{|l|}{ Type of CS } \\
\hline Emergency & $68(72.3)$ & $26(27.7)$ & 1.00 & & & \\
\hline Elective & $3(75.0)$ & $1(25.0)$ & $\begin{array}{l}0.87(0.09- \\
8.76)\end{array}$ & 0.91 & & \\
\hline \multicolumn{7}{|l|}{ PROM } \\
\hline No & $62(72.9)$ & $23(27.1)$ & 1.00 & & & \\
\hline Yes & $9(69.2)$ & $4(30.8)$ & $\begin{array}{l}1.20(0.34- \\
4.27)\end{array}$ & 0.78 & & \\
\hline \multicolumn{7}{|l|}{ Prior CS } \\
\hline No & $50(67.6)$ & $24(32.4)$ & 1.00 & & 1.00 & \\
\hline Yes & $21(87.50)$ & $3(12.50)$ & $\begin{array}{l}0.30(0.08- \\
1.10)\end{array}$ & 0.07 & $\begin{array}{l}0.26(0.06- \\
1.09)\end{array}$ & 0.07 \\
\hline \multicolumn{7}{|c|}{ Use of antiseptic } \\
\hline No & $12(46.2)$ & 14(53.8) & 1.00 & & 1.00 & \\
\hline
\end{tabular}


Table 9: Common bacterial isolates from post-caesarean septic wounds from Mothers in Hoima Regional Referral Hospital, Uganda.

\begin{tabular}{lccc}
\hline Pathogen & Frequency & Percent & 95\%CI \\
\hline Pseudomonas aeruginosa & 43 & 15.3 & $11.5-20.0$ \\
\hline Staphylococcus aureus & 81 & 28.8 & $23.8-34.4$ \\
E. colit & 59 & 21.0 & $16.6-26.2$ \\
Proteus mirabilis & 24 & 8.5 & $5.8-12.5$ \\
Staphylococcus spp & 35 & 12.5 & $9.1-16.9$ \\
Klebsiella pneumoniae† & 39 & 13.9 & $10.3-18.5$ \\
\hline
\end{tabular}

†coliforms

Figures 


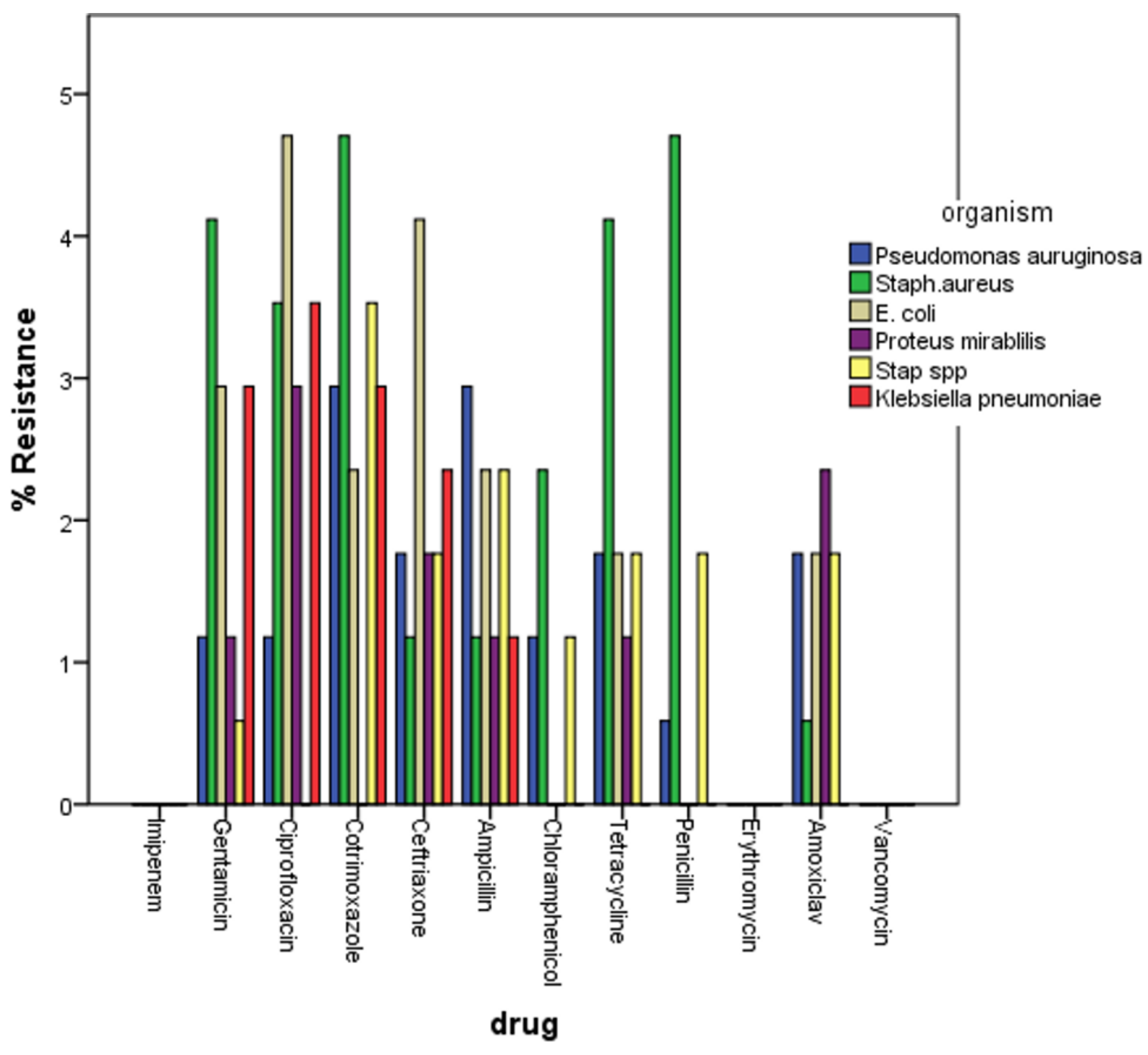

Figure 1

Resistance pattern of bacterial isolates against major antibiotics among mothers attending post-natal ward Hoima Regional Referral Hospital, Western Uganda 


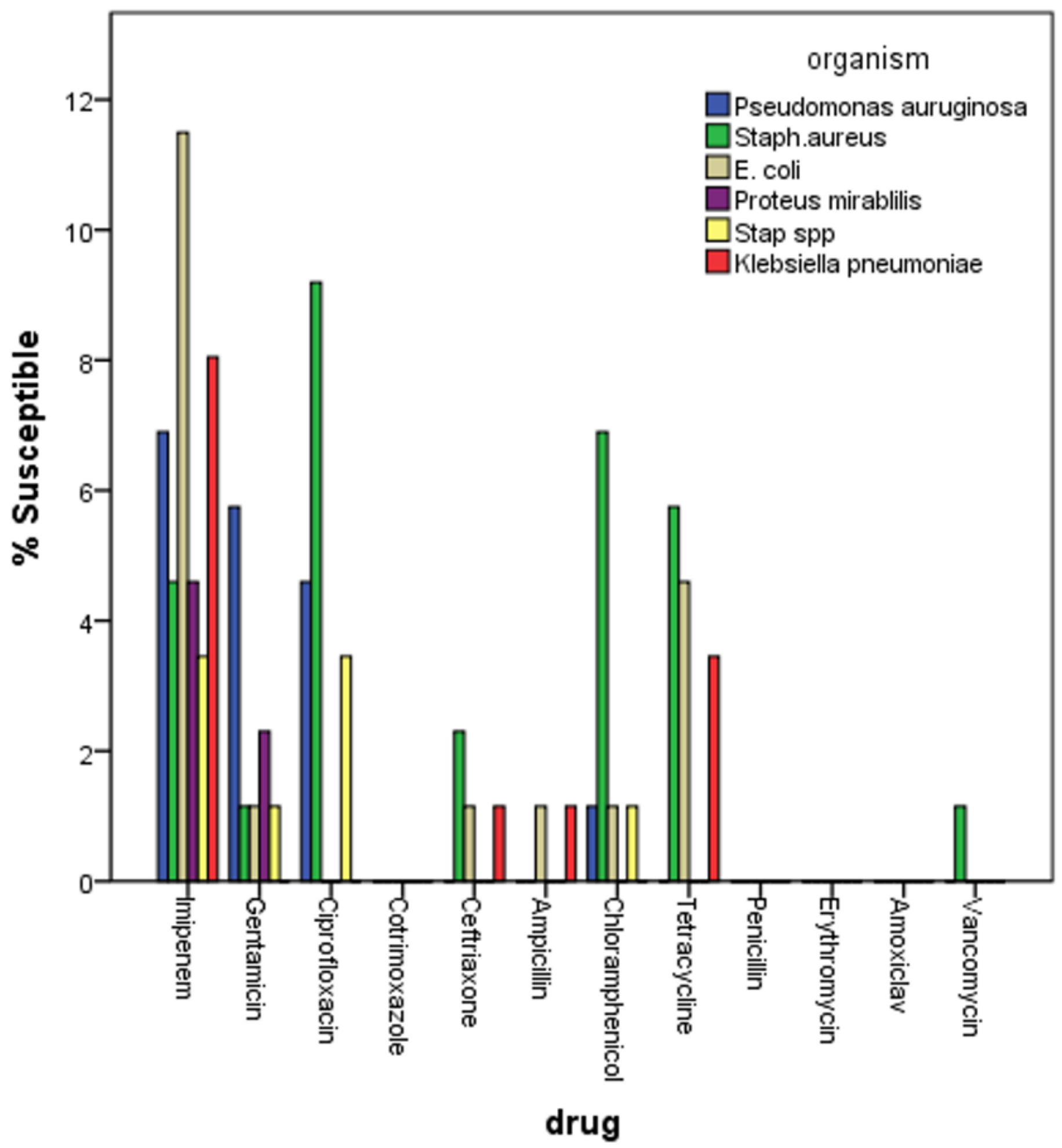

Figure 2

Susceptibility pattern of bacterial isolates against major antibiotics among mothers attending post-natal ward Hoima Regional Referral Hospital, Western Uganda 